\title{
The Relationship between Income,
}

\section{Consumption and GDP of Asian Countries: A Panel Analysis}

\author{
Sima Rani Dey \\ Bangladesh Institute of Governance and Management, Bangladesh \\ simabd33o@gmail.com
}

This paper attempts to scrutinize the co-integration relationship between consumption, income and GDP per capita in panel data series. We have applied unit root test, co-integration test and F MOLS estimation technique to analyze the data. Data covers 11 Asian countries of three income categories - lower middle income, upper middle income and high income. The study contemplated the annual observations of 35 years from 1980 to 2014 . Study revealed that the association between consumption and income is stronger in lower and upper middle income countries. The low level of income determines its maximum use predominantly for consumption. The relation between consumption, income and GDP per capita is stronger for lower middle income countries, thereby the countries with higher income generally tend to make big investments.

Key Words: income, consumption, GDP, panel unit roots, panel cointegration

JEL Classification: C23, D31, E 21

https://doi.org/10.26493/1854-6935.17.113-127

\section{Introduction}

Rationale people always think at margin and cut their coat according to their cloth. This proverb clearly supports the famous Keynesian theory, where consumption is a function of income. Consumption behavior is mostly determined by income level, better income level ensures satisfactory level of consumption. But the influences of regional and cultural differences cannot be ignored to explain people's consumption behavior (how consumers like to spend) as well as their easy access to better earning source. Katona $(1960,22)$, for example, claimed that the ability to buy is not enough, because consumption expenditures are also dependent on the willingness to buy. This willingness is influenced by individual rationales, such as attitudes and prospects of future income, and by the state of the whole economy, which create a general optimistic (positive) or pessimistic (negative) environment. 
Income affects consumption choices and it's very obvious, then these consumption expenditures directly affect gross domestic product (GDP) in any economy. Because consumption is one of the principal components of GDP, especially in less developed countries.

Generally, people never spend their whole earning just for consumption and this remained amount is said as savings in economic theory. So, income is a sum of consumption and savings (which can be said as investment as well). In this point, Keynes $(2009,158)$ suggested that individuals tend to increase consumption as their income increases, but to a lesser extent. This fundamental psychological law states that as the level of income increases, the difference between income and consumption increases as well.

This paper investigates the relationships between consumption, income and GDP but in per capita form on panel data (sum of cross-section and time series data) for income categorized countries-lower middle income, upper middle income and high income. To ascertain the long run association between consumption, income and GDP, we conducted three different tests of cointegration and FMOLS to measure the strength of relationship between income and consumption.

The main purpose of this paper was to analyze the differences that may appear in association income and consumption variables when differences of income level and country regions exists. This study is emphasizing in a small portion of this broad macroeconomic issue, because there are many other variables rather than income that can influence people's consumption decisions and gross domestic product (GDP).

\section{Data Description}

To ascertain the relationship pattern between consumption, income and GDP per capita during 1980-2014, eleven (11) countries of Asia were taken into account on the basis of the data availability. These countries were again divided in 3 categories of income such as lower middle income, upper middle income and high income countries. World Bank classification is used to classify the countries on income base (table 1) following Diacon and Maha (2015).

The variables of interest in this study were: private consumption per capita (expressed in the form of household final consumption expenditure per capita), adjusted net national income per capita and GDP per capita as a proxy of the level of standard of living. All the variables are in natural logarithm form. 
TABLE 1 Lists of Country Panel Data

\begin{tabular}{lll}
\hline $\begin{array}{l}\text { Lower-Middle Income } \\
\text { Countries }\end{array}$ & $\begin{array}{l}\text { Upper-Middle Income } \\
\text { Countries }\end{array}$ & High Income Countries \\
\hline Us \$ 1,006-3,955 & U \$ 3,956-12,235 & > us\$ 12,236 \\
\hline Bangladesh (Southern) & Malaysia (South-eastern) & Singapore (South-eastern) \\
India (Southern) & Thailand (South-eastern) & Japan (Eastern) \\
Sri Lanka (Southern) & China (Eastern) & South Korea (Eastern) \\
Indonesia (South-eastern) & & \\
Philippines (South-eastern) & & \\
\hline
\end{tabular}

NOTES For 2018 fiscal year, GNi per capita is calculated using the World Bank Atlas method. Based on data from The World Bank (http://data.worldbank.org).

TABLE 2 Descriptive Statistics, by Logarithmic Variable

\begin{tabular}{lcccccccr}
\hline Variable & \multicolumn{2}{l}{ Lower-middle income } & & \multicolumn{2}{l}{ Upper-middle income } & & \multicolumn{2}{c}{ High income } \\
\cline { 2 - 3 } & $(1)$ & $(2)$ & & $(1)$ & $(2)$ & & $(1)$ & $(2)$ \\
\hline GDP & 6.549 & 0.725 & & 7.550 & 1.050 & & 9.720 & 0.860 \\
Con & 6.742 & 0.639 & & 7.270 & 0.874 & & 9.480 & 0.600 \\
Inc & 6.469 & 0.740 & & 7.320 & 1.000 & & 9.540 & 0.837 \\
\hline
\end{tabular}

Notes Column headings are as follows: (1) mean, (2) standard deviation. Definitions: GDP - GDP per capita (current US\$), Con - household final consumption expenditure per capita (current Us\$), Inc - adjusted net national income per capita (current US\$).

World Bank provides household final consumption expenditure per capita in constant 2010 us $\$$ for all panel except China. Household final consumption expenditure per capita in constant 2010 U $\$$ data of China was only available from year 1990 in WDI but our data span starts from 1980. So we have taken consumption expenditure per capita data of China in constant 2005 US $\$$ from 1980-2014. Then we transformed household consumption expenditure per capita data of all panel in current us $\$$ using the inflation conversion factors (Sahr 2016), to have the same unit measures. But the other variables (adjusted net national income per capita and GDP per capita) are already in current Us\$. All the tests were performed in EViews 9.

Major shortcoming of cross-country time series analysis is data quality and comparability. Data collection techniques and coverage, in particular, are not unique and can vary from country to country and from one period to another within the same country. To overcome the problem of data lacking, we selected into analysis only the countries with consistent 
data. Because of the different definitions of some indicators (the different measures of gross domestic product per capita, for example), we could not mix the data sources and we have confined to a single one - the World Bank.

The World Bank's country income classification is dynamic: a country can move annually to another category (according to its level of income) and the reference values of gross national income (GNI) per capita vary in time. In our analysis, we have chosen the most recent classification, available for the 2018 fiscal year, to allocate each considered country to a given panel (lower middle, upper middle- and high-income countries). The analyzed time series overlaps over a period of 35 years, from 1980 to 2014 .

\section{Background of the Study}

With the development of an economy (i.e. higher GDP), purchasing power increases with increased per capita income. Then income raises the consumption expenditures and also raises the standard of living. This flow of income, consumption and GDP per capita is clearly evident from the figures of income classified countries.

The average net income and the average GDP per capita increased stronger than consumption from 2007 (figure 1) but before that they had to consume $100 \%$ of their income with no savings. In upper middle income countries, after 1993, the net average income started to increase with a small drop (from the 1998 to 2004). Though their GDP per capita was unaffected during the period unless the crisis year (2008 to 2009). From 1991, the average net income and the average GDP per capita were always remained above the consumption constantly (figure 3 ). Although the growth rate of consumption expenditure in lower middle income countries is a bit faster than high income countries.

The average net income and the average GDP per capita increased stronger than consumption from 2007 (figure 1) but before that they had to consume $100 \%$ of their income with no savings. In upper middle income countries, after 1993, the net average income started to increase with a small drop (from the 1998 to 2004). Though their GDP per capita was unaffected during the period unless the crisis year (2008 to 2009). From 1991, the average net income and the average GDP per capita were always remained above the consumption constantly (figure 3). Although the growth rate of consumption expenditure in lower middle income countries is a bit faster than high income countries. 


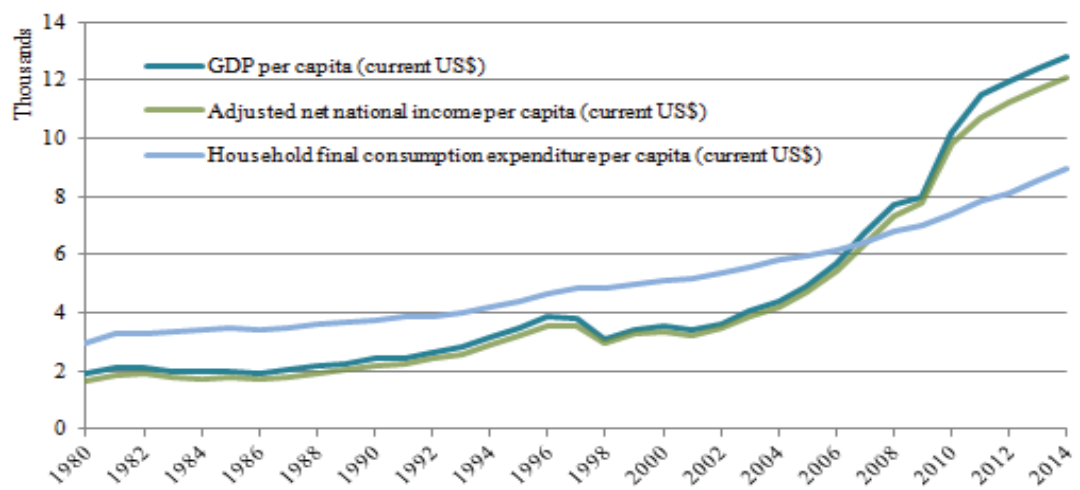

FIGURE 1 Lower-Middle Income Countries (Based on data from The World Bank, http://data.worldbank.org)

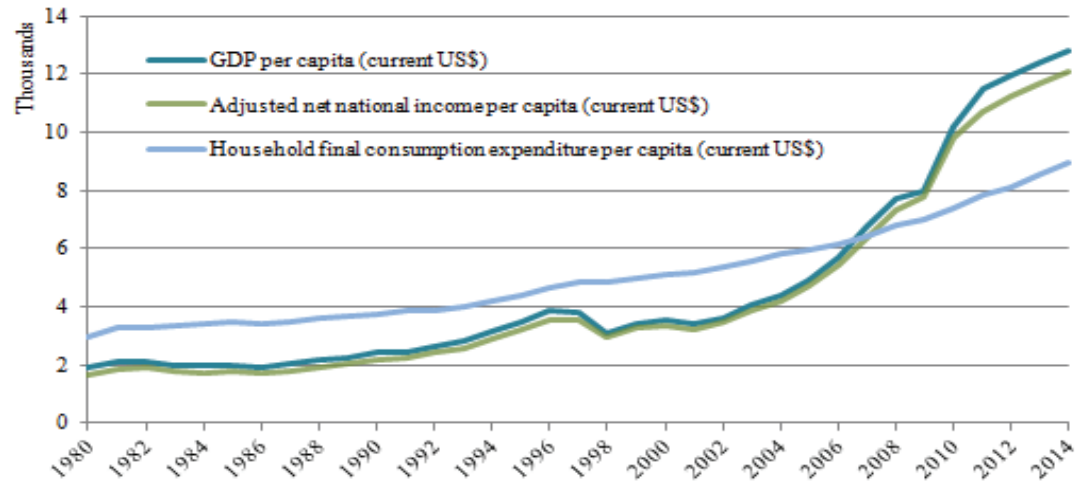

FIGURE 2 Upper-Middle Income Countries (Based on data from The World Bank, http://data.worldbank.org)

The remarkable thing from the above three graphs is that the average net income and the average GDP per capita of upper middle and high income countries has responded quickly during the crisis year than lower middle income countries. But the slope of per capita consumption has increased more (lower middle income countries) than other countries.

Generally, people do not response instantly with increased income and GDP. Because of having habituated with a living standard, it is difficult to change it all on a sudden. So for the adjustment of increased expenditure, people have to cut their savings with the hope that income will restore to the previous value.

Several noticeable facts are evident from South-Asian countries graph- 


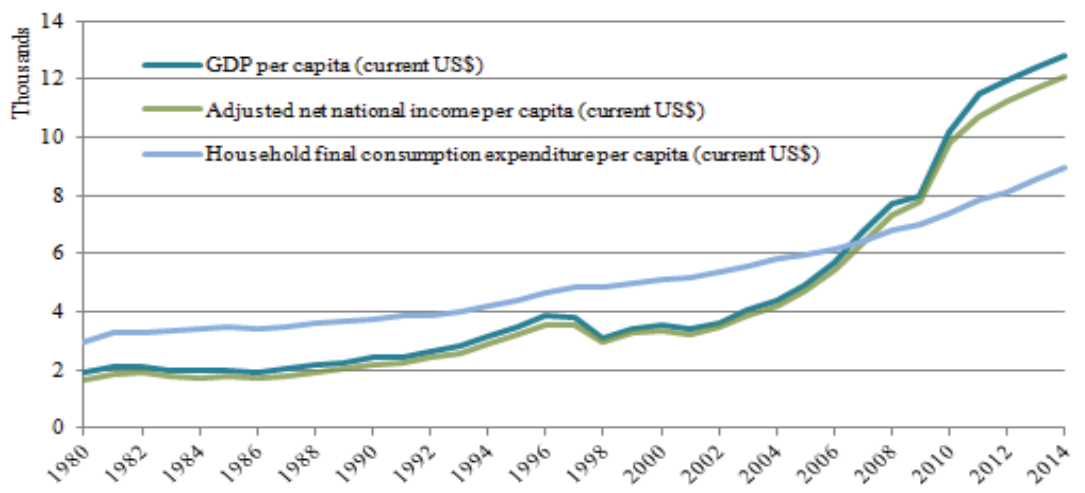

FIGURE 3 High Income Countries (Based on data from The World Bank, http://data.worldbank.org)

ical presentations. Household consumption expenditure per capita was higher than GDP and income per capita as well as their consumption expenditure is increasing consistently with increasing GDP and income per capita from 2008 (lower middle income). Though GDP per capita was higher since 1990's but income per capita experienced fluctuations and started to rise than consumption expenditure per capita from 2005 (upper middle income).

After 1988's, GDP and income per capita is greater than consumption expenditure per capita but experiencing a small drop at the beginning of 2000, the income per capita again started to increase. This characteristics of high income countries of Asia is consistent with Keynes' remarks which is - the difference between income and consumption grows along with the rising levels of income and consumption, with some fluctuations in high income countries. It is very obvious that consumption expenditure increases with increasing level of income and also increases savings that indirectly increases the gross domestic product.

\section{Econometric Methodology}

Existence of no unit root in panel data is required to ignore the dubious result of the estimation. Thus, our econometric methodology proceeds in four stages. First, we implement common (Levin, Lin, and Chu 2002 and Breitung 2000) and individual (Im, Pesaran, and Shin 2003, ADF-Fisher Chi-square and Pp-Fisher Chi-square define by Maddala and Wu 1999 and Choi 2001) unit root test to ascertain the order of integration of the variables. 
We mainly implement the following equation:

$$
\operatorname{Con}_{i t}=\alpha_{1}+\alpha_{2} \text { Inc }_{i t}+\varepsilon_{i 1 t} .
$$

Then

$$
\operatorname{GDP}_{i t}=\beta_{1}+\beta_{2} \operatorname{Con}_{i t}+\beta_{3} \operatorname{Inc}_{i t}+\varepsilon_{2 i t} .
$$

Second, conditional on finding that all variables are integrated of order one; we test for panel cointegration to confirm the existence of long run relationship. Given that each variable is integrated of order one, we test for panel cointegration equilibrium relationship between the variables using the approach of Pedroni (1999), Kao (1999) which is Engle-Granger (1987) two step residual based test and Fisher which a combined Johansen test of cointegration.

Pedroni (1999) considers the following time series panel regression

$$
y_{i t}=\alpha_{i t}+\delta_{i t} t+X_{i} \beta_{i}+e_{i t},
$$

where $y_{i t}$ and $X_{i t}$ are the observable variables with dimension of $(N *$ $T) \times 1$ and $(N * T) \times m$, respectively. Pedroni (1999) derives seven panel cointegration test statistics as well. Of these seven statistics, four are based on within-dimension, and three are based on between-dimension. The seven Pedroni's statistics for testing cointegration are:

Panel $v$-statistic:

$$
Z_{\nu}=T^{2} N^{\frac{3}{2}}\left(\sum_{i=1}^{N} \sum_{i=1}^{T} \hat{L}_{11 i}^{-2} \hat{\varepsilon}_{i, t-1}^{2}\right)^{-1} .
$$

Panel $\rho$-statistic:

$$
Z_{\rho}=T \sqrt{N}\left(\sum_{i=1}^{N} \sum_{i=1}^{T} \hat{L}_{11 i}^{-2} \hat{\varepsilon}_{i, t-1}^{2}\right)^{-1} \sum_{i=1}^{N} \sum_{i=1}^{T} \hat{L}_{11 i}^{-2}\left(\hat{\varepsilon}_{i, t-1} \Delta \hat{\varepsilon}_{i, t}-\hat{\lambda}_{i}\right) .
$$

Panel $t$-statistic (non-parametric):

$$
\dot{Z}_{t}=\left(\sigma_{N, T}^{2} \sum_{i=1}^{N} \sum_{i=1}^{T} \hat{L}_{11 i}^{-2} \hat{\varepsilon}_{i, t-1}^{2}\right)^{-\frac{1}{2}} \sum_{i=1}^{N} \sum_{i=1}^{T} \hat{L}_{11 i}^{-2}\left(\hat{\varepsilon}_{i, t-1} \Delta \hat{\varepsilon}_{i, t}-\hat{\lambda}_{i}\right) .
$$

Panel $t$-statistic (parametric):

$$
\left.\dot{Z}_{t}=\left(\tilde{s}_{N, T}^{2} \sum_{i=1}^{N} \sum_{i=1}^{T} \hat{L}_{11 i}^{-2} \hat{\varepsilon}_{i, t-1}^{2}\right)^{-\frac{1}{2}} \sum_{i=1}^{N} \sum_{i=1}^{T} \hat{L}_{11 i}^{-2} \hat{\varepsilon}_{i, t-1} \hat{\varepsilon}_{i, t-1}-\Delta \hat{\varepsilon}^{i, t}\right) .
$$


Group $\rho$-statistic:

$$
\tilde{Z}_{\rho}=T \sqrt{N} \sum_{i=1}^{N}\left(\sum_{i=1}^{T} \hat{\varepsilon}_{i, t-1}^{2}\right)^{-1} \sum_{i=1}^{T}\left(\hat{\varepsilon}_{i, t-1} \Delta \hat{\varepsilon}_{i, t}-\hat{\lambda}_{i}\right) .
$$

Group $t$-statistic (non-parametric):

$$
\tilde{Z}_{t}=\sqrt{N} \sum_{i=1}^{N}\left(\hat{\sigma}_{i}^{2} \sum_{i=1}^{T} \hat{\varepsilon}_{i, t-1}^{2}\right)^{-\frac{1}{2}} \sum_{i=1}^{T}\left(\hat{\varepsilon}_{i, t-1} \Delta \hat{\varepsilon}_{i, t}-\hat{\lambda}_{i}\right) .
$$

Group $t$-statistic (parametric):

$$
\tilde{Z}_{t}=\sqrt{N} \sum_{i=1}^{N}\left(\sum_{i=1}^{T} \hat{s}_{i}^{2} \hat{\varepsilon}_{i, t-1}^{2}\right)^{-\frac{1}{2}} \sum_{i=1}^{T} \hat{\varepsilon}_{i, t-1} \Delta \hat{\varepsilon}_{i, t} .
$$

Now if the variables are cointegrated, the next task to estimate the long-run association of the variables. Various econometric methodologies exists or are proposed for testing cointegrated vectors. For example, the parametric panel dynamic ordinary least squares (DOLS) of Kao and Chiang (2000) which is promising in small samples and performs well in cointegrated panels. But the limitation of the Dols method is that it does not allow the cross-sectional heterogeneity in the alternative hypothesis. So, to address the cross-sectional heterogeneity, endogenity and serial correlation problem in order to obtain consistent and asymptotically unbiased estimates, we preferred Pedroni $(2000 ; 2001)$ proposed the group mean fully modified ordinary least squares (F MOLS) estimator.

The panel FMOLS estimator is given as:

$$
\hat{\beta}_{\mathrm{FMOLS}}=\frac{1}{2} \sum_{i=1}^{N}\left[\left(\sum_{i=1}^{T}\left(X_{i, t}-\bar{X}_{i}\right)^{2}\right)^{-1}\left(\sum_{i=1}^{T}\left(X_{i, t}-\bar{X}_{i}\right) W_{i, t}-T \hat{\gamma}_{i}\right)\right] \text {, }
$$

where

$$
W_{i, t}=W_{i, t}-\bar{W}_{i}-\frac{\hat{\omega}_{2,1, i}}{\hat{\omega}_{2,2, i}} \Delta X_{i, t} \wedge \hat{\gamma}_{i}=\hat{\Gamma}_{2,1, i}+\hat{\Omega}_{2,1, i}-\frac{\hat{\omega}_{2,1, i}}{\hat{\omega}_{2,2, i}}\left(\hat{\Gamma}_{2,2, i}+\hat{\Omega}_{2,1, i}^{o}\right) .
$$

\section{Empirical Results}

Following econometric methodology, firstly we tested for the stationarity of the variables which assume common and individual unit root process (table 3).

In the analyzed panels (lower middle, upper middle, high income and total countries), we found that all the three variables - consumption, in- 
TABLE 3 Panel Unit Root Tests

\begin{tabular}{|c|c|c|c|c|c|c|c|c|c|c|}
\hline \multirow{3}{*}{$\begin{array}{l}\text { (1) } \\
\text { (a) }\end{array}$} & \multirow{3}{*}{$\begin{array}{l}\text { (2) } \\
\text { Con }\end{array}$} & \multirow{3}{*}{$\begin{array}{l}\text { Test* }^{*} \\
\text { LLC }\end{array}$} & \multicolumn{4}{|c|}{ Level } & \multicolumn{4}{|c|}{ 1st Difference } \\
\hline & & & \multicolumn{2}{|c|}{ Constant $\left(p^{* *}\right)$} & \multicolumn{2}{|c|}{ Con. + Trend $\left(p^{\star *}\right)$} & \multicolumn{2}{|c|}{ Constant $\left(p^{* *}\right)$} & \multicolumn{2}{|c|}{ Con. + Trend $\left(p^{* *}\right)$} \\
\hline & & & 5.8714 & 1.000 & 0.9722 & 0.8345 & -8.9557 & 0.000 & -11.328 & 0.000 \\
\hline & & IPS & 7.1305 & 1.000 & 0.7070 & 0.7602 & -8.5622 & 0.000 & -10.449 & 0.000 \\
\hline & & $\mathrm{ADF}$ & 1.1492 & 0.999 & 10.069 & 0.4344 & 77.707 & 0.000 & 113.005 & 0.000 \\
\hline & & $\mathrm{PP}$ & 1.1493 & 0.999 & 13.331 & 0.2057 & 82.807 & 0.000 & 314.154 & 0.000 \\
\hline & Inc & LLC & 4.8829 & 1.000 & 0.5882 & 0.7218 & -7.4383 & 0.000 & $-7 \cdot 3747$ & 0.000 \\
\hline & & IPS & 7.0254 & 1.000 & 1.8469 & 0.9676 & -8.2154 & 0.000 & -8.4075 & 0.000 \\
\hline & & $\mathrm{ADF}$ & 0.1538 & 1.000 & 3.0167 & 0.9810 & 76.008 & 0.000 & 71.640 & 0.000 \\
\hline & & $\mathrm{PP}$ & 0.1632 & 1.000 & 2.7118 & 0.9874 & 78.501 & 0.000 & 72.411 & 0.000 \\
\hline & GDP & LLC & 4.9333 & 1.000 & 1.1912 & 0.8832 & -8.3674 & 0.000 & -8.4598 & 0.000 \\
\hline & & IPS & 7.1008 & 1.000 & 2.5529 & 0.9947 & -8.3133 & 0.000 & -8.5216 & 0.000 \\
\hline & & $\mathrm{ADF}$ & 0.1137 & 1.000 & 1.7469 & 0.9979 & 77.045 & 0.000 & 72.679 & 0.000 \\
\hline & & $\mathrm{PP}$ & 0.1170 & 1.000 & 1.9902 & 0.9964 & 78.517 & 0.000 & 73.112 & 0.000 \\
\hline \multirow[t]{12}{*}{ (b) } & Con & LLC & 3.6975 & 0.999 & 1.6712 & 0.9527 & -4.0156 & 0.000 & -4.9082 & 0.000 \\
\hline & & IPS & 4.3450 & 1.000 & 1.2712 & 0.8982 & -2.6185 & 0.004 & -4.2405 & 0.000 \\
\hline & & $\mathrm{ADF}$ & 1.0066 & 0.985 & 4.8764 & 0.5598 & 19.780 & 0.003 & 27.239 & 0.000 \\
\hline & & $\mathrm{PP}$ & 0.5989 & 0.996 & 1.7990 & 0.9372 & 30.940 & 0.000 & 24.409 & 0.000 \\
\hline & Inc & LLC & 1.5395 & 0.938 & 0.1608 & 0.5639 & -5.2143 & 0.000 & -2.5266 & 0.005 \\
\hline & & IPS & 3.0380 & 0.999 & 0.1241 & 0.5494 & -4.8403 & 0.000 & -4.0012 & 0.000 \\
\hline & & $\mathrm{ADF}$ & 0.6911 & 0.995 & 5.1320 & 0.5270 & 33.149 & 0.000 & 26.068 & 0.000 \\
\hline & & $\mathrm{PP}$ & 0.4875 & 0.998 & 2.6674 & 0.8493 & 33.795 & 0.000 & 25.288 & 0.000 \\
\hline & GDP & LLC & 1.5312 & 0.937 & -0.1275 & 0.4493 & -5.4984 & 0.000 & -4.9883 & 0.000 \\
\hline & & IPS & 3.0794 & 0.999 & 0.3291 & 0.6290 & -4.9337 & 0.000 & -4.0985 & 0.000 \\
\hline & & $\mathrm{ADF}$ & 0.6236 & 0.996 & 3.8189 & 0.7012 & 34.119 & 0.000 & 26.068 & 0.000 \\
\hline & & $\mathrm{PP}$ & 0.4261 & 0.998 & 2.9814 & 0.8112 & 34.150 & 0.000 & 25.528 & 0.000 \\
\hline
\end{tabular}

come and GDP per capita - are non-stationary at level and have unit roots in both cases (intercept and intercept plus trend). Further, all the data series are integrated of first order and became stationary after their 1st differencing.

Secondly, we performed cointegration tests since all the variables are integrated of order one in all cases. To investigate the long-run relationship between the variables, we conducted Pedroni Test (Table 4). Pedroni $(1999,666)$ proved that the null hypothesis of no cointegration between variables is rejected when the calculated panel statistics have large negative values, except for panel v-statistics which take large positive values in this case.

In our study, there is strong evidence that consumption and income are 
TABLE 3 Continued from the previous page

\begin{tabular}{|c|c|c|c|c|c|c|c|c|c|c|}
\hline \multirow{3}{*}{$\begin{array}{l}\text { (1) } \\
\text { (c) }\end{array}$} & \multirow{3}{*}{$\begin{array}{l}\text { (2) } \\
\text { Con }\end{array}$} & \multirow{3}{*}{$\begin{array}{l}\text { Test }^{*} \\
\text { LLC }\end{array}$} & \multicolumn{4}{|c|}{ Level } & \multicolumn{4}{|c|}{ 1st Difference } \\
\hline & & & \multicolumn{2}{|c|}{ Constant $\left(p^{* *}\right)$} & \multicolumn{2}{|c|}{ Con. + Trend $\left(p^{* *}\right)$} & \multicolumn{2}{|c|}{ Constant $\left(p^{\star *}\right)$} & \multicolumn{2}{|c|}{ Con. + Trend $\left(p^{* *}\right)$} \\
\hline & & & -5.463 & 0.000 & 0.4137 & 0.6605 & -4.6658 & 0.000 & -5.6408 & 0.000 \\
\hline & & IPS & -2.692 & 0.003 & 3.0096 & 0.9987 & -4.68535 & 0.000 & -5.7665 & 0.000 \\
\hline & & $\mathrm{ADF}$ & 19.893 & 0.003 & 0.2834 & 0.9996 & 32.450 & 0.000 & 37.551 & 0.000 \\
\hline & & PP & 20.946 & 0.002 & 0.3025 & 0.9995 & 32.777 & 0.000 & 98.684 & 0.000 \\
\hline & Inc & LLC & -2.606 & 0.004 & -0.0063 & 0.4975 & -5.5137 & 0.000 & -5.2129 & 0.000 \\
\hline & & IPS & -0.956 & 0.169 & 0.6833 & 0.7528 & -4.7199 & 0.000 & $-4 \cdot 3288$ & 0.000 \\
\hline & & $\mathrm{ADF}$ & 9.1376 & 0.166 & 2.7349 & 0.8413 & 32.638 & 0.000 & 27.686 & 0.000 \\
\hline & & PP & 6.1911 & 0.402 & 1.5105 & 0.9588 & 34.686 & 0.000 & 26.943 & 0.000 \\
\hline & GDP & LLC & -2.261 & 0.012 & -0.0129 & 0.4949 & -5.4773 & 0.000 & -5.2990 & 0.000 \\
\hline & & IPS & -0.7810 & 0.217 & 0.7112 & 0.7615 & -4.5152 & 0.000 & -4.1333 & 0.000 \\
\hline & & $\mathrm{ADF}$ & 8.8999 & 0.179 & 2.8643 & 0.8257 & 31.051 & 0.000 & 26.380 & 0.000 \\
\hline & & PP & 6.3659 & 0.383 & 1.4956 & 0.9598 & 33.546 & 0.000 & 25.966 & 0.000 \\
\hline \multirow[t]{12}{*}{ (d) } & Con & LLC & 2.9769 & 0.998 & 1.4853 & 0.9313 & -10.957 & 0.000 & -13.374 & 0.000 \\
\hline & & IPS & 5.7269 & 1.000 & 2.6740 & 0.9963 & -9.5170 & 0.000 & -12.198 & 0.000 \\
\hline & & $\mathrm{ADF}$ & 22.048 & 0.457 & 15.229 & 0.8522 & 129.94 & 0.000 & 177.79 & 0.000 \\
\hline & & PP & 22.694 & 0.419 & 15.433 & 0.8430 & 146.52 & 0.000 & 437.25 & 0.000 \\
\hline & Inc & LLC & 2.9659 & 0.998 & 0.5281 & 0.7013 & -10.673 & 0.000 & -8.9912 & 0.000 \\
\hline & & IP S & 5.7899 & 1.000 & 1.6543 & 0.9510 & -10.528 & 0.000 & -9.9407 & 0.000 \\
\hline & & $\mathrm{ADF}$ & 9.9825 & 0.986 & 10.884 & 0.9764 & 141.79 & 0.000 & 125.39 & 0.000 \\
\hline & & PP & 6.8418 & 0.999 & 6.8898 & 0.9991 & 146.98 & 0.000 & 124.64 & 0.000 \\
\hline & GDP & LLC & 2.8529 & 0.998 & 0.6786 & 0.7513 & -11.392 & 0.000 & -11.043 & 0.000 \\
\hline & & IPS & 5.9369 & 1.000 & 2.2496 & 0.9878 & -10.535 & 0.000 & -10.038 & 0.000 \\
\hline & & $\mathrm{ADF}$ & 9.6371 & 0.989 & 8.4302 & 0.9958 & 142.21 & 0.000 & 125.13 & 0.000 \\
\hline & & PP & 6.9090 & 0.999 & 6.4673 & 0.9995 & 146.21 & 0.000 & 124.60 & 0.000 \\
\hline
\end{tabular}

NOTES Column headings are as follows: (1) panel, (2) variable. Row headings are as follows: (a) lowermiddle income, (b) upper-middle income, (c) high income, (d) all countries. ${ }^{*}$ Levin, Lin, and Chu Test (LLC) and Breitung assume common unit root process; Im, Pesaran and Shin (IPS), ADF-Fisher Chisquare and PP-Fisher Chi-square assume individual unit root process. ${ }^{*}$ Probabilities for Fisher tests are computed using an asymptotic Chi-square distribution. All other tests assume asymptotic normal.

cointegrated only in lower middle income countries when an intercept is considered in the time series according to Pedroni cointegration test. However, the calculated tests values reported a combined interpretation in every considered case (for every panel and both associations between variables). We considered the criterion reported by most of the results for each particular situation.

To check the robustness of our cointegration output, we also performed additional tests of cointegration using the methodology proposed by Kao and Fisher (table 5). According to Kao cointegration test, cointegration 
TABLE 4 Pedroni Panel Cointegration Tests

\begin{tabular}{llrrrrrrrr}
\hline & Test & \multicolumn{2}{c}{ Low $\left(p^{* *}\right)$} & Upper-middle $\left(p^{* *}\right)$ & \multicolumn{2}{c}{ High $\left(p^{* *}\right)$} & \multicolumn{2}{c}{ All countries $\left(p^{* *}\right)$} \\
\hline (1) Con-Inc & (a) & 1.8906 & 0.0293 & 0.1060 & 0.4578 & 1.5418 & 0.0616 & 1.4613 & 0.0720 \\
& (b) & -1.4518 & 0.0733 & -0.2045 & 0.4190 & -0.5922 & 0.2768 & -1.2598 & 0.1039 \\
& (c) & -1.5896 & 0.0560 & -0.4301 & 0.3335 & -0.4384 & 0.3305 & -1.8461 & 0.0324 \\
& (d) & -1.4621 & 0.0719 & -1.4830 & 0.0690 & -2.3838 & 0.0086 & -2.9064 & 0.0018 \\
& (e) & -2.2710 & 0.0116 & 0.2552 & 0.6007 & 0.3946 & 0.6534 & -1.0802 & 0.1400 \\
& (f) & -2.8673 & 0.0021 & -0.3493 & 0.3634 & 0.1898 & 0.5753 & -2.0777 & 0.0189 \\
& (g) & -3.4985 & 0.0002 & -1.3473 & 0.0889 & -2.5952 & 0.0047 & -3.3545 & 0.0004 \\
& (h) & 2.4719 & 0.0067 & -0.2494 & 0.5985 & 1.4247 & 0.0771 & 2.0791 & 0.0188 \\
& (i) -2.9270 & 0.0017 & -0.9317 & 0.1757 & -0.5002 & 0.3084 & -1.9229 & 0.0272 \\
& (j) & -2.9006 & 0.0019 & -1.0755 & 0.1411 & -0.3709 & 0.3553 & -2.3573 & 0.0092 \\
& (k) -3.2718 & 0.0005 & -1.5005 & 0.0667 & -2.0208 & 0.0216 & -3.3370 & 0.0004 \\
\hline Con-Inc-GDP & (a) & 0.6378 & 0.2618 & 0.9811 & 0.1633 & 2.2162 & 0.0133 & 1.1724 & 0.1205 \\
& (b) -0.1726 & 0.4315 & -0.4642 & 0.3212 & -0.2969 & 0.3833 & -0.0641 & 0.4744 \\
& (c) -0.7667 & 0.2216 & -0.9241 & 0.1777 & -0.2103 & 0.4167 & -0.7352 & 0.2311 \\
& (d) -0.6955 & 0.2433 & -0.8675 & 0.1928 & -0.7179 & 0.2364 & -0.7472 & 0.2275 \\
& (e) -0.6825 & 0.2474 & -0.0820 & 0.4673 & 0.6338 & 0.7369 & -0.1204 & 0.4521 \\
& (f) -2.4204 & 0.0078 & -0.8524 & 0.1970 & 0.1673 & 0.5665 & -0.9587 & 0.1688 \\
& (g) -2.3558 & 0.0092 & -0.6719 & 0.2508 & -1.5783 & 0.0572 & -1.9716 & 0.0243 \\
& (h) 1.0825 & 0.1395 & 1.1949 & 0.1161 & 2.6124 & 0.0045 & 2.1188 & 0.0171 \\
& (i) -1.1850 & 0.1180 & -0.5665 & 0.2855 & -0.2071 & 0.4179 & -0.7324 & 0.2319 \\
& (j) -1.9470 & 0.0258 & -0.9632 & 0.1677 & -0.2980 & 0.3828 & -1.3825 & 0.0834 \\
& (k) -1.9192 & 0.0275 & -0.8800 & 0.1894 & -1.3633 & 0.0864 & -1.7299 & 0.0418 \\
\hline
\end{tabular}

Continued on the next page

relationship exists between consumption, income and GDP in all panels. Also, Kao test confirmed an association between consumption and income - for upper middle income, high income and all countries, except lower middle income countries.

In addition, applying Fisher cointegration test, the long run association between consumption and income is ensured in the case of lower middle and upper middle income countries when only intercept is considered. Whereas, cointegration relationship exists between consumption and income in all panels when intercept and trend is considered in the time series. The long run relationship is exists only in lower middle income countries when intercept is considered. While, the long-run association between consumption, income and GDP in all the cases - lower middle, upper middle, high income and all countries when intercept and trend is considered in the time series.

Conclusions of the cointegration results are presented below (table 6). Strong long run relationship between consumption and income in lower 
TABLE 4 Continued from the previous page

\begin{tabular}{|c|c|c|c|c|c|c|c|c|c|c|}
\hline \multirow{2}{*}{ (2) } & \multirow[b]{2}{*}{ Con-Inc } & \multirow{2}{*}{$\frac{\text { Test }}{\text { (a) }}$} & \multicolumn{2}{|c|}{ Low $\left(p^{* *}\right)$} & \multicolumn{2}{|c|}{ Upper-middle $\left(p^{* *}\right)$} & \multicolumn{2}{|c|}{$\operatorname{High}\left(p^{* *}\right)$} & \multicolumn{2}{|c|}{ All countries $\left(p^{* *}\right)$} \\
\hline & & & -0.3343 & 0.6310 & -1.3268 & 0.9077 & 0.2866 & 0.3872 & 5.7049 & 0.0000 \\
\hline & & (b) & 0.8494 & 0.8022 & 0.7687 & 0.7790 & 0.6668 & 0.7476 & -0.0437 & 0.4826 \\
\hline & & (c) & 0.4445 & 0.6717 & 0.3561 & 0.6391 & 0.3732 & 0.6455 & -0.7816 & 0.2172 \\
\hline & & (d) & 0.4443 & 0.6716 & -1.7624 & 0.0390 & -1.5666 & 0.0586 & -2.3807 & 0.0086 \\
\hline & & (e) & -0.1813 & 0.4280 & 1.1049 & 0.8654 & 1.3183 & 0.9063 & 0.4639 & 0.6787 \\
\hline & & (f) & -1.2331 & 0.1088 & 0.4380 & 0.6693 & 0.8728 & 0.8086 & -0.2849 & 0.3878 \\
\hline & & (g) & -2.0368 & 0.0208 & -1.7944 & 0.0364 & -1.6634 & 0.0481 & -2.3363 & 0.0097 \\
\hline & & (h) & 0.3436 & 0.3656 & -1.6320 & 0.9487 & 0.0536 & 0.4786 & 4.9098 & 0.0000 \\
\hline & & (i) & -1.0098 & 0.1563 & 0.2092 & 0.5829 & 0.7121 & 0.7618 & -0.9828 & 0.1628 \\
\hline & & (j) & -1.8523 & 0.0320 & -0.3656 & 0.3573 & 0.4063 & 0.6577 & -2.1793 & 0.0147 \\
\hline & & (k) & -2.4298 & 0.0076 & -2.3993 & 0.0082 & -1.9059 & 0.0283 & -4.1455 & 0.0000 \\
\hline & Con-Inc-G DP & (a) & -0.5447 & 0.7071 & 1.1385 & 0.1275 & 1.9709 & 0.0244 & 3.8527 & 0.0001 \\
\hline & & (b) & 0.2810 & 0.6107 & -0.5696 & 0.2845 & -0.0195 & 0.4922 & 0.7928 & 0.7861 \\
\hline & & (c) & -0.8559 & 0.1960 & -1.4977 & 0.0671 & -0.7441 & 0.2284 & -0.2056 & 0.4185 \\
\hline & & (d) & -0.7135 & 0.2378 & -1.5375 & 0.0621 & -1.7908 & 0.0367 & -1.3568 & 0.0874 \\
\hline & & (e) & 0.1514 & 0.5602 & 0.3106 & 0.6220 & 1.2509 & 0.8945 & 1.1587 & 0.8767 \\
\hline & & (f) & -1.8784 & 0.0302 & -0.8342 & 0.2021 & 0.2833 & 0.6116 & 0.1187 & 0.5473 \\
\hline & & (g) & -1.8695 & 0.0308 & -0.8595 & 0.1950 & -2.4811 & 0.0065 & -2.4090 & 0.0080 \\
\hline & & (h) & -0.2941 & 0.6157 & 1.2805 & 0.1002 & 1.9431 & 0.0260 & 2.9291 & 0.0017 \\
\hline & & (i) & -0.4935 & 0.3108 & -0.5441 & 0.2932 & 0.5611 & 0.7127 & 0.4288 & 0.6660 \\
\hline & & (j) & -1.8798 & 0.0301 & -1.4811 & 0.0693 & -0.2213 & 0.4124 & -0.9988 & 0.1589 \\
\hline & & (k) & -1.8114 & 0.0350 & -1.5096 & 0.0656 & -2.5634 & 0.0052 & -2.9392 & 0.0016 \\
\hline
\end{tabular}

NOTES Row headings are as follows: (1) constant, (2) constant + trend, (a) panel v-statistic, (b) panel rhostatistic, (c) panel PP-statistic, (d) panel ADF-statistic, (e) group rho-statistic, (f) group P P-statistic, (g) group ADF-statistic, (h) weighted panel v-s, (i) weighted panel rho-s, (j) weighted panel PP-s, (k) weighted panel ADF-S.

TABLE 5 Kao and Fisher Panel Cointegration Tests

\begin{tabular}{|c|c|c|c|c|c|c|c|c|c|c|}
\hline \multirow[b]{2}{*}{ (1) } & \multirow[b]{2}{*}{ Con-Inc } & \multirow{2}{*}{$\frac{\text { Test }}{\text { (a) }}$} & \multicolumn{2}{|c|}{$\operatorname{Low}\left(p^{* *}\right)$} & \multicolumn{2}{|c|}{ Upper-middle $\left(p^{* *}\right)$} & \multicolumn{2}{|c|}{$\operatorname{High}\left(p^{* *}\right)$} & \multicolumn{2}{|c|}{ All countries $\left(p^{* *}\right)$} \\
\hline & & & -0.1677 & 0.4334 & -3.2472 & 0.0006 & -3.0125 & 0.0013 & -2.4617 & 0.0069 \\
\hline & & (b) & 5.471 & 0.7062 & 5.561 & 0.4741 & 14.95 & 0.0207 & 25.98 & 0.1664 \\
\hline & Con-Inc-GDP & (a) & -3.6541 & 0.0001 & -2.2981 & 0.0108 & -4.4524 & 0.0000 & -2.4150 & 0.0079 \\
\hline & & (c) & 5.600 & 0.6919 & 13.33 & 0.0381 & 14.02 & 0.0294 & 32.95 & 0.0342 \\
\hline \multirow[t]{2}{*}{ (2) } & Con-Inc & (b) & 2.147 & 0.9762 & 3.654 & 0.7233 & 7.044 & 0.3168 & 12.84 & 0.8839 \\
\hline & Con-Inc-GDP & (c) & 2.481 & 0.9626 & 8.029 & 0.2360 & 6.650 & 0.3544 & 17.16 & 0.6425 \\
\hline
\end{tabular}

NOTES Row headings are as follows: (1) constant, (2) constant + trend, (a) Kao, (b) Fisher (at most 1), (c) Fisher (at most 2). The results are presented from Trace Test; because data are annual, we have chosen 1 Lag interval; probabilities for Fisher Test are computed using asymptotic Chi-square distribution.

middle income and upper middle income panels, but weaker for high income countries. Also, a significant long run association is found between consumption, income and GDP in lower middle income country panels while weaker for other panels. Sample of all countries are mixed for both associations of variables in the analyzed periods. Lastly, condi- 
TABLE 6 Summary of Cointegration Tests

\begin{tabular}{|c|c|c|c|c|c|c|c|c|c|}
\hline & \multirow[t]{2}{*}{ Test } & \multicolumn{4}{|c|}{ Constant } & \multicolumn{4}{|c|}{ Constant + Trend } \\
\hline & & (1) & (2) & (3) & (4) & (1) & (2) & (3) & (4) \\
\hline \multirow[t]{3}{*}{ Con-Inc } & (a) & Yes & No & No & Yes & No & No & No & Yes \\
\hline & (b) & No & Yes & Yes & Yes & - & - & - & - \\
\hline & (c) & Yes & Yes & No & Yes & Yes & Yes & Yes & Yes \\
\hline \multirow[t]{3}{*}{ Con-Inc-GDP } & (a) & No & No & No & No & No & No & No & No \\
\hline & (b) & Yes & Yes & Yes & Yes & - & - & - & - \\
\hline & (d) & Yes & No & No & No & Yes & Yes & Yes & Yes \\
\hline
\end{tabular}

NOTES Column headings are as follows: (1) lower-mid, (2) upper-mid, (3) high, (4) all. Row headings are as follows: (a) Pedroni, (b) Kao, (c) Fisher (at most 1), (d) Fisher (at most 2). Results are presented at $5 \%$ level of significance.

TABLE 7 Full Modified ols Estimates

\begin{tabular}{llll}
\hline Variable & Country Grouping & Consumption exp. & Income \\
\hline Consumption exp. & Lower middle income & & $0.525303(0.0000)$ \\
& Upper middle income & & $0.583777(0.0000)$ \\
& High income & & $0.489537(0.0000)$ \\
& All panel & & $0.538597(0.0000)$ \\
\hline GDP & Lower middle income & $0.223537(0.0146)$ & $0.867593(0.0000)$ \\
& Upper middle income & $0.044654(0.6188)$ & $1.011292(0.0000)$ \\
& High income & $0.198412(0.0000)$ & $0.927010(0.0000)$ \\
& All panel & $0.208005(0.0000)$ & $0.904013(0.0000)$ \\
\hline
\end{tabular}

tional on finding cointegration we calculate panel fully modified ordinary least squares (FMOLS) estimate of the coefficients.

Table 7 represents the results of FMOLS test of the country grouping. All variables are in natural logarithm form. The estimated coefficients from the long-run relationship are quite significant at $5 \%$ level of significance. Income is a key factor of consumption expenditure in all level of income countries. And per capita consumption expenditure and per capita income is highly influential component of per capita GDP in all income grouping countries.

\section{Conclusions}

The study presents the relationship between the income, consumption and GDP for a panel of Asian countries over the periods of 1980-2014. In this regard, the research employed essential econometric techniques such as panel unit root tests, panel cointegration tests and FMOLS test to understand the long run relationship between the studied variables. Moreover, the link between the income, consumption and GDP is one of the most examined association in economics. 
Cointegration test results establishes the existence of long run equilibrium relation among the targeted series which is in line with Khan and Ahmad (2014). The study revealed that, there is an association between consumption and income. However, the level of income has a greater importance for consumption for the individuals from countries with lower middle and upper middle income levels, but the association between these two variables is weaker in the countries with a high income level. This is also logical in the sense that people from these two-income group (lower middle and upper middle income) spend their maximum on consumption rather than savings and investment opportunities. Large numbers of middle-income households live hand-to-mouth lifestyles with little margin for unexpected negative events (Baker and Yannelis 2017). In fact, sometimes their consumption is more than the income. Generally, variables that predict income growth also predict consumption growth except Japan. In other economies, predictable income growth and predictable consumption growth move in proportion with one another (Campbell and Mankiw 1991). The overall study results support the Keynesian law which demonstrates that consumption is a function of income.

On the other hand, the association between consumption, income and GDP was found significant in all considered panel of countries when intercept and trend is considered. In fact, this relationship became more accentuated for the lower middle income countries. This may be because the economies of lower middle income countries, typically depends on their domestic consumption. Even it also said that uniqueness of Asian economies growth is that their economic growth is mainly driven by the consumption. Above facts are highly influential both in forming the microeconomic support of future economic models and also in designing government policy to insure against income disruptions.

\section{References}

Baker, S. R., and C. Yannelis. 2017. 'Income Changes and Consumption: Evidence from the 2013 Federal Government Shutdown.' Review of Economic Dynamics 23 (1): 99-124.

Breitung, J. 2000. 'The Local Power of Some Unit Root Tests for Panel Data.' In Nonstationary Panels, Panel Cointegration, and Dynamic Panels, edited by B. H. Baltagi, T. B. Fomby, and R. Carter Hill, 161-78. Advances in Econometrics 15. Amsterdam: JAI Press.

Campbell, J. Y., and N. G. Mankiw. 1991. 'The Response of Consumption to Income: A Cross-Country Investigation.' European Economic Review 35 (4): 723-67. 
Choi, I. 2001. 'Unit Root Tests for Panel Data.' Journal of International Money and Finance 20 (2): 249-72.

Diacon, P. E., and L. E. Maha. 2015. 'The Relationship between Income, Consumption and GDP: A Time-Series, Cross-Country Analysis.' Procedia Economics and Finance 23:1535-43.

Im, K. S., M. H. Pesaran, and Y. Shin. 2003. 'Testing for Unit Roots in Heterogeneous Panels.' Journal of Econometrics 115 (1): 53-74.

Kao, C. 1999. 'Spurious Regression and Residual-Based Tests for Cointegration in Panel Data.' Journal of Econometrics 90 (1): 1-44.

Kao, C., and M. H. Chiang. 200o. 'On the Estimation and Inference of a Cointegrated Regression in Panel Data.' In Nonstationary Panels, Panel Cointegration, and Dynamic Panels, edited by B. H. Baltagi, T. B. Fomby, and R. Carter Hill, 179-222. Advances in Econometrics 15. Amsterdam: JA I Press.

Katona, G. 1960. The Powerful Consumer: Psychological Studies of the American Economy. New York: McGraw-Hill.

Keynes, J. M. 2009. Teoria generală a ocupării forței de muncă, a dobânzii şi a banilor. Bucharest: Publica.

Khan, M. A., and I. Ahmad. 2014. 'An Empirical Study into the Relation of Income and Consumption Using Cross-Sectional Data.' Paper presented at the ASEE 2014 Zone I Conference, Bridgepeort, CT, 3-5 April.

Levin, A., C. F. Lin, and C. Chu. 2002. 'Unit Root Tests in Panel Data: Asymptotic and Finite-Sample Properties.' Journal of Econometrics 108 (1): 1-24.

Maddala, G. S., and S. Wu. 1999. 'A Comparative Study of Unit Root Tests with Panel Data and a New Simple Test.' Oxford Bulletin of Economics and Statistics 61 (Special Issue): 631-52.

Pedroni, P. 1999. 'Critical Values for Cointegration Tests in Heterogeneous Panel with Multiple Regressors.' Oxford Bulletin of Economics and Statistics 61 (Special Issue): 653-70.

Pedroni, P. 2000. 'Fully-Modified ols for Heterogeneous Cointegration Panel.' Advances in Econometrics 15:93-130.

Pedroni, P. 2001. 'Purchasing Power Parity Tests in Cointegrated Panels.' Review of Economics and Statistics 83 (4): 727-31.

Sahr, S. 2016. 'Inflation Conversion Factors For Years 1774 to Estimated 2028, in Dollars of Recent Years.' https://liberalarts.oregonstate.edu/spp /polisci/research/inflation-conversion-factors

This paper is published under the terms of the Attribution-

NonCommercial-NoDerivatives 4.o International (CC B Y-NC-ND 4.0)

License (http://creativecommons.org/licenses/by-nc-nd/4.o/). 